\title{
Trends in healthcare utilization among older Americans with colorectal cancer: A retrospective database analysis Kathleen Lang ${ }^{1}$, Lisa M Lines ${ }^{1}$, David W Lee ${ }^{2}$, Jonathan R Korn ${ }^{1}$, Craig C Earle ${ }^{3}$ and Joseph Menzin*1
}

Address: ${ }^{1}$ Boston Health Economics, Inc, Waltham, MA, USA, ${ }^{2}$ GE Healthcare, Waukesha, WI USA and ${ }^{3}$ Institute for Clinical Evaluative Sciences, Toronto, ON, Canada

Email: Kathleen Lang - klang@bhei.com; Lisa M Lines - llines@gmail.com; David W Lee - David.W.Lee@ge.com; Jonathan R Korn - jkorn@bhei.com; Craig C Earle - craig.earle@ices.on.ca; Joseph Menzin* - jmenzin@bhei.com

* Corresponding author

Published: 10 December 2009

BMC Health Services Research 2009, 9:227 doi:10.1 186/1472-6963-9-227
Received: 18 December 2008

Accepted: 10 December 2009

This article is available from: http://www.biomedcentral.com//472-6963/9/227

(c) 2009 Lang et al; licensee BioMed Central Ltd.

This is an Open Access article distributed under the terms of the Creative Commons Attribution License (http://creativecommons.org/licenses/by/2.0), which permits unrestricted use, distribution, and reproduction in any medium, provided the original work is properly cited.

\begin{abstract}
Background: Analyses of utilization trends (cost drivers) allow us to understand changes in colorectal cancer (CRC) costs over time, better predict future costs, identify changes in the use of specific types of care (eg, hospice), and provide inputs for cost-effectiveness models. This retrospective cohort study evaluated healthcare resource use among US Medicare beneficiaries diagnosed with CRC between 1992 and 2002.

Methods: Cohorts included patients aged $66+$ newly diagnosed with adenocarcinoma of the colon $(n=52,371)$ or rectum $(n=18,619)$ between 1992 and 2002 and matched patients from the general Medicare population, followed until death or December 3I, 2005. Demographic and clinical characteristics were evaluated by cancer subsite. Resource use, including the percentage that used each type of resource, number of hospitalizations, and number of hospital and skilled nursing facility days, was evaluated by stage and subsite. The number of office, outpatient, and inpatient visits per person-year was calculated for each cohort, and was described by year of service, subsite, and treatment phase. Hospice use rates in the last year of life were calculated by year of service, stage, and subsite for CRC patients who died of CRC.
\end{abstract}

Results: CRC patients (mean age: $\mathbf{7 7 . 3}$ years; $\mathbf{4 4 . 9 \%}$ male) used more resources than controls in every category $(P<.00 \mathrm{I})$, with the largest differences seen in hospital days and home health use. Most resource use (except hospice) remained relatively steady over time. The initial phase was the most resource intense in terms of office and outpatient visits. Hospice use among patients who died of CRC increased from $20.0 \%$ in 1992 to $70.5 \%$ in 2004 , and age-related differences appear to have evened out in later years.

Conclusion: Use of hospice care among CRC decedents increased substantially over the study period, while other resource use remained generally steady. Our findings may be useful for understanding CRC cost drivers, tracking trends, and forecasting resource needs for CRC patients in the future. 


\section{Background}

Colorectal cancer (CRC) is the third-most common cancer type in the United States (not including basal and squamous cell skin cancer), and the third-leading cause of cancer deaths among both men and women[1]. The total annual cost of CRC care in the US population over age 65 has been estimated at $\$ 8$ billion in 2002 dollars[2]. To our knowledge, no previous studies have reported comprehensive data on temporal trends in healthcare utilization for CRC patients, although studies have been published on hospice use and end-of-life care among cancer patients (including some CRC patients) [3-11].

In addition to aiding in the understanding of cost drivers, the study of healthcare utilization patterns may lead to cost-saving strategies in the care of CRC (eg, a shift from more-expensive settings to less-expensive settings), and may inform studies regarding the quality of care received by CRC patients as indicated by quality markers including hospice, skilled nursing, and home health care[10]. Inpatient hospitalization is generally the largest cost driver for any disease; therefore, it is vital to be aware of temporal trends in hospitalization use in order to understand changes in costs over time and to predict costs in the future[12]. Finally, decisions on CRC screening can be based on cost-effectiveness analyses and models that rely on CRC cost and utilization studies, and such decisions may depend on having accurate data inputs into these models.

The goals of this study were to analyze the sociodemographic and clinical characteristics of a large cohort of CRC patients, describe healthcare utilization associated with CRC, and assess temporal trends in resource utilization.

\section{Methods \\ Data Source}

The data source for this study was the linked Surveillance, Epidemiology, and End Results (SEER)-Medicare database, in which Medicare claims are linked to SEER registry data as part of a collaborative project between the National Cancer Institute and the Centers for Medicare and Medicaid Services. Complete details of the linkage of the SEER and Medicare data have been described elsewhere $[13,14]$. The study's use of SEER-Medicare data was approved by the National Cancer Institute, assuring patient confidentiality. No other ethics board review was required. In the SEER-Medicare database, patient demographic characteristics (such as age, sex, and race/ethnicity), disease characteristics (such as stage), and resource use details are obtained from hospitals, outpatient clinics, laboratories, private practitioners, nursing homes, hospices, death certificates, autopsy reports, and Medicare claims data[15]. Part A of the Medicare program covers inpatient hospitalizations, skilled nursing facility (SNF) and home health care after a hospital stay, and hospice care. Approximately $99 \%$ of Medicare beneficiaries are enrolled in Part A. During this study's analysis period, Medicare did not cover outpatient prescription drugs. Medicare Part B covers physician services (except for routine visits), outpatient services, diagnostic tests, emergency room visits, durable medical equipment (DME), laboratory services, home health care that does not follow a hospital stay, and other medical services and supplies. Approximately $95 \%$ of Medicare beneficiaries are enrolled in Part B[13].

\section{Patient Selection and Follow-up CRC Cohort}

All patients aged 66 years and older with a new diagnosis of malignant adenocarcinoma of the colon, rectum, or anus (ie, presence of a SEER cancer site recode value between 15 and 27 and one of the following ICD-O-3 histology codes: 8140, 8210-11, 8220-21, 8260-63, 8470, $8480-81$, or 8490 ) reported to a SEER registry between January 1, 1992 and December 31, 2002 were identified for possible inclusion in the CRC cohort. The index date for each patient was defined as the date of his or her CRC diagnosis.

We excluded patients who were enrolled in a health maintenance organization (HMO) at any point from 12 months pre-index through follow-up. Until recently, HMOs were not required to submit claims for specific services received by their enrollees, so including these patients might have underestimated the total utilization for the sample. We also excluded patients who were not eligible for Part A and B Medicare benefits at any point from 12 months pre-index through follow-up or who were eligible for Medicare benefits based on end-stage renal disease or disability. We excluded patients who had any prior history of cancer, were initially diagnosed with CRC at the time of death or autopsy, were not able to be matched to an appropriate comparator (based on age, sex, and geographic region), or were characterized as having stage 0 or unknown stage disease.

\section{Comparison Cohort}

Patients in the comparison cohort were randomly selected from a 5\% sample of Medicare beneficiaries residing in SEER areas who had not been reported to any of the SEER registries as having CRC. As with CRC patients, comparison patients were excluded if they were enrolled in an HMO or were not eligible for Medicare Part A and B benefits at any point from 12 months before index through follow-up. Comparison cohort patients were not required to have used services in order to be selected for inclusion, and they were allowed to develop cancers other than CRC after their index date. One comparison patient of identical 
age, sex, and geographic region was matched to each CRC patient and assigned the same index date so that both patients were followed over the same time period. When more than one match was possible, comparators were chosen at random.

\section{Follow-up Period}

Study patients were followed to evaluate outcomes from their index date until death or the end of the Medicare claims data (December 31, 2005), whichever came first. When a person died before his or her matched comparator, we continued to follow the comparator to record his or her utilization until death or the end of the Medicare claims data, whichever came first.

\section{Study Measures}

Medicare claims were scanned to identify resource utilization, including physician office visits, outpatient hospital or clinic use, inpatient hospitalization, SNF utilization, and use of home health care and hospice. DME claims were excluded because of incomplete diagnostic coding.

\section{Data Analyses}

The demographic and clinical characteristics of both cohorts were described, including Deyo-Charlson comorbidity scores, which were calculated for the pre-index 12month period for each person and excluded cancerrelated comorbidities[16]. Healthcare utilization was analyzed by cancer subsite (colon or rectal), age at diagnosis, stage at diagnosis, and year of service. The percentages of patients receiving each type of care, number of visits, and lengths of stay were evaluated over the entire follow-up period. We calculated attributable use rates for each phase by subtracting utilization among persons in the comparison cohorts from that among persons in the CRC cohorts over the same time period. This resulted in estimates of the excess numbers of visits per person-year, which were reported by treatment phase for office, outpatient, and inpatient utilization.

Resource use by phase was estimated as follows: 1) terminal-phase resource use was assigned first, with the terminal phase defined as the final year of life (all resource use was considered terminal for patients surviving for less than 13 months after diagnosis); 2) the initial phase was the period, up to 12 months in duration, after diagnosis and before the last year of life among those who lived at least 13 months after diagnosis; and 3) the continuing phase was the period between the first and last year of life among patients with at least 36 months of survival. Resource use by treatment phase was generated by year of service from 1993-2002, the years during which it was possible to fully evaluate each phase.
For our analysis of the use of hospice care, we selected from our overall CRC cohort only those patients who died of CRC during the study period. We then calculated the percentage of patients who used hospice care in their last year of life and reported these data by cancer subsite, year of service, and age at death.

All statistical tests for differences between study and control cohorts were obtained using the Wilcoxon rank-sum test using the Statistical Analysis Software (SAS) package (Version 9.1, SAS Institute, Cary, NC).

\section{Results}

\section{Patient Demographic and Clinical Characteristics}

Selected demographic and clinical characteristics of the CC, RC, combined CRC, and comparison cohorts are shown in Table 1. In the combined CRC and comparison cohorts, the average patient was approximately 77 years of age, $45 \%$ were male, and $86 \%$ were white. The mean \pm SD Deyo-Charlson comorbidity score (excluding cancer) was $0.5 \pm 1.0$ for cancer patients and $0.4 \pm 0.9$ for controls; scores were fairly consistent across all years (1992: $0.3 \pm$ $0.8 ; 2002: 0.5 \pm 1.0$ in 2002 [data not shown]).

Across all years, CC was most commonly diagnosed at stage II, whereas RC was most commonly diagnosed at stage I. Interestingly, among both CC and RC patients, age at diagnosis changed considerably over the period of analysis. In $1992,43.7 \%$ of CC patients were aged $66-74$ years, $40.2 \%$ were $75-84$, and $16.1 \%$ were aged 85 years or more. The corresponding distribution in 2002 was $45.9 \%$, $35.5 \%$, and $18.7 \%$, indicating a trend toward older age at diagnosis (data not shown). In 1992, the age distribution was similar for RC patients: $45.4 \%$ were aged $66-74$ years, $40.7 \%$ were $75-84$, and $13.8 \%$ were 85 years or older. By 2002 , there were more $75-84$ year olds (44.3\%) diagnosed with RC than $66-74$ year olds $(40.5 \%)$, and the proportion of those aged 85+ years had increased to $15.2 \%$ (data not shown).

\section{Healthcare Utilization}

As would be expected, both CC and RC patients used significantly more healthcare resources than matched comparison patients (Table 2). We did not detect a pattern of differences in resource use in the comparison cohort when examined by stage of their matched cancer patient, thus the comparison cohort is shown as a whole. Compared to non-CRC patients, CC and RC patients had an average of about 2 years less follow-up time because of their higher mortality rate. Despite the shorter follow-up, more CRC patients were hospitalized and spent more days in the hospital, more received home health care, and more spent more time in a SNF (all $P<.001)$. 
Table I: Demographic and clinical characteristics of patients with CRC and matched controls

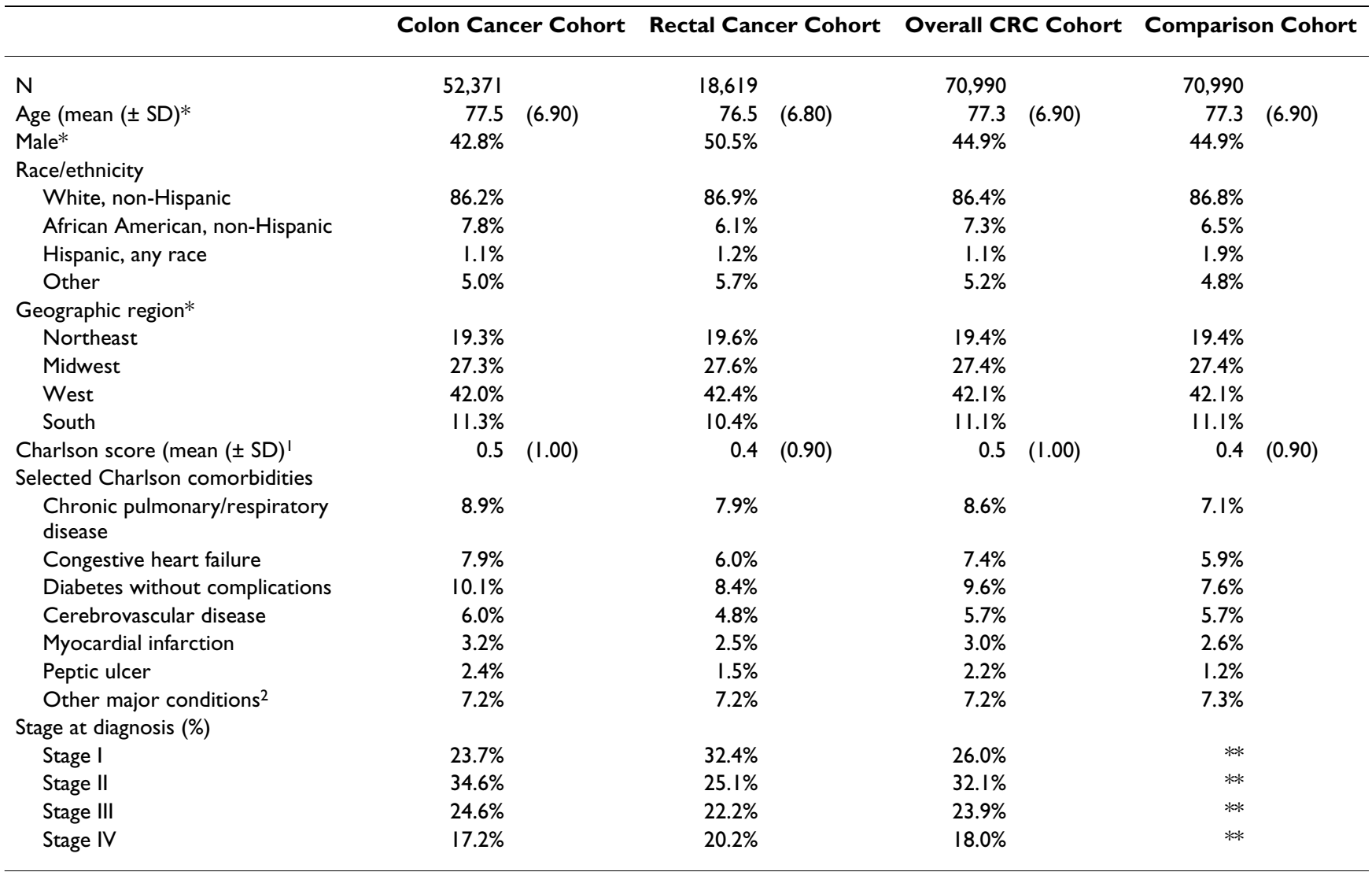

Source: Authors' calculations based on SEER-Medicare data, 1992-2005. IModified Charlson comorbidity index: excludes cancer-related comorbidities. ${ }^{2}$ Other major conditions include rheumatologic disease, mild liver disease, diabetes with complications, major liver disease, peripheral vascular disease, dementia, renal disease, hemiplegia or paraplegia, and AIDS.

*Variables used in matching cohorts

**Data not available/not applicable

Resource utilization differed somewhat by cancer stage at diagnosis, with stage II and III patients having the most intense absolute service utilization rates by most measures (Table 2). However, when calculated per survival month, stage IV patients had higher utilization rates in all areas. For example, stage IV patients spent more than 2 days per month of follow-up in a hospital or SNF (approximately 1.5 days in a hospital and 0.5 days in a SNF per month), compared to less than 1 day per month of follow-up among patients diagnosed at stages I-III. Use of home health care services ranged between approximately 50$60 \%$ for all stages (vs. 35-36\% among non-CRC patients), with higher use rates among RC patients.

Figure 1 shows annualized trends in the excess number of office (a) and outpatient clinic (b) visits and inpatient stays (c) by cohort, treatment phase, and year of service (ie, trends in resource use among CRC patients relative to matched comparison patients). Trends in attributable use rates reflect changes among both CRC patients and their comparators. For example, between 1995-1996, office vis- its decreased by 0.8 visits per person-year among RC patients in the terminal phase and increased by 4.2 visits among comparison patients in the terminal phase, leading to a relative decrease of 5 visits per person year in the number of attributable office visits.

The initial phase of treatment was the most resource intense among both CC and RC patients for all 3 types of resource use, with RC patients having higher excess use rates in most cases in the initial and terminal phases.

Among patients who died of CRC during the study period, an overall proportion of $50.5 \%$ of CC and $53.0 \%$ of RC patients used hospice services in the last year of life. Among CC patients, the proportion of all decedents who used hospice care in the last year of life increased from $21.6 \%$ in 1992 to $71.0 \%$ in 2002 . Among RC patients, the increase was from $16.1 \%$ in 1992 to $69.2 \%$ in 2002 . In earlier years, persons over age 85 were less likely to use hospice services than younger patients, but this difference 
Table 2: Resource use among patients with CRC, by stage and overall, vs. matched controls

\begin{tabular}{|c|c|c|c|c|c|c|c|c|c|c|c|c|c|}
\hline \multirow[t]{2}{*}{ Variables } & \multicolumn{8}{|c|}{ CRC Patients } & \multicolumn{2}{|c|}{$\begin{array}{c}\text { Overall CRC } \\
\text { Cohort }\end{array}$} & \multicolumn{2}{|c|}{$\begin{array}{c}\text { Comparison } \\
\text { Cohort }\end{array}$} & \multirow[t]{2}{*}{ Difference } \\
\hline & $\begin{array}{r}\text { Stage } \\
\text { I }\end{array}$ & & $\begin{array}{r}\text { Stage } \\
\text { II }\end{array}$ & & $\begin{array}{r}\text { Stage } \\
\text { III }\end{array}$ & & $\begin{array}{r}\text { Stage } \\
\text { IV }\end{array}$ & & & & & & \\
\hline \multicolumn{14}{|l|}{$\begin{array}{l}\text { Colon Cancer } \\
\text { Cohort }\end{array}$} \\
\hline $\mathrm{N}$ & $|2,43|$ & & 18,095 & & 12,859 & & 8,986 & & $52,37 \mid$ & & 52,371 & & \\
\hline $\begin{array}{l}\text { Mean }( \pm S D) \\
\text { months of follow-up }\end{array}$ & 61.1 & $(39.8)$ & 56.4 & $(40.9)$ & 44.7 & $(38.1)$ & 12.7 & $(19.3)$ & 47.1 & $(40.7)$ & 68.6 & $(39.8)$ & -21.5 \\
\hline Inpatient use & $94.4 \%$ & & $97.7 \%$ & & $97.5 \%$ & & $94.3 \%$ & & $96.3 \%$ & & $68.2 \%$ & & $28.1 \%$ \\
\hline $\begin{array}{l}\text { Mean }( \pm S D) \\
\text { hospitalizations }\end{array}$ & 3.6 & (3.3) & 3.6 & (3.1) & 3.5 & $(3.0)$ & 2.3 & $(2.0)$ & 3.4 & (3.0) & 2.4 & $(3.1)$ & 1.0 \\
\hline $\begin{array}{l}\text { Mean }( \pm S D) \\
\text { hospital days }\end{array}$ & 26.3 & $(31.8)$ & 28.5 & $(30.3)$ & 27.9 & $(26.8)$ & 20.1 & $(18.9)$ & 26.4 & $(28.4)$ & 15.1 & $(25.7)$ & 11.3 \\
\hline SNF use & $35.8 \%$ & & $41.2 \%$ & & $38.6 \%$ & & $30.0 \%$ & & $37.4 \%$ & & $29.0 \%$ & & $8.4 \%$ \\
\hline $\begin{array}{l}\text { Mean }( \pm S D) \\
\text { SNF days }\end{array}$ & 13.3 & $(50.9)$ & 15.1 & $(5 । .7)$ & 12.5 & (37.4) & 6.6 & $(18.4)$ & 12.5 & $(44.2)$ & 9.7 & $(33.0)$ & 2.9 \\
\hline $\begin{array}{l}\text { Outpatient clinic } \\
\text { use }\end{array}$ & $94.5 \%$ & & $91.9 \%$ & & $92.0 \%$ & & $77.4 \%$ & & $90.1 \%$ & & $89.9 \%$ & & $0.1 \%$ \\
\hline Office visit use & $99.7 \%$ & & $99.7 \%$ & & $99.6 \%$ & & $98.8 \%$ & & $99.5 \%$ & & $96.2 \%$ & & $3.3 \%$ \\
\hline $\begin{array}{l}\text { Home health care } \\
\text { use }\end{array}$ & $48.4 \%$ & & $52.9 \%$ & & $53.5 \%$ & & $45.7 \%$ & & $50.7 \%$ & & $36.3 \%$ & & $14.4 \%$ \\
\hline \multicolumn{14}{|l|}{$\begin{array}{l}\text { Rectal Cancer } \\
\text { Cohort }\end{array}$} \\
\hline $\mathrm{N}$ & 6,041 & & 4,681 & & 4,134 & & 3,763 & & 18,619 & & 18,619 & & \\
\hline $\begin{array}{l}\text { Mean }( \pm S D) \\
\text { months of follow-up }\end{array}$ & 61.0 & (39.9) & 52.0 & $(40.0)$ & 46.0 & (37.1) & 11.6 & $(17.3)$ & 45.4 & $(40.1)$ & 70.6 & $(40.2)$ & -25.2 \\
\hline Inpatient use & $92.8 \%$ & & $96.8 \%$ & & $98.0 \%$ & & $89.7 \%$ & & $94.3 \%$ & & $67.5 \%$ & & $26.9 \%$ \\
\hline $\begin{array}{l}\text { Mean }( \pm S D) \\
\text { hospitalizations }\end{array}$ & 3.6 & (3.4) & 3.7 & $(3.0)$ & 3.8 & $(3.0)$ & 2.0 & $(2.0)$ & 3.3 & (3.0) & 2.4 & $(3.2)$ & 1.0 \\
\hline $\begin{array}{l}\text { Mean }( \pm S D) \\
\text { hospital days }\end{array}$ & 26.1 & $(30.4)$ & 29.5 & $(28.1)$ & 30.2 & $(28.0)$ & 16.7 & $(16.6)$ & 25.9 & $(27.4)$ & 15.2 & $(26.0)$ & 10.8 \\
\hline SNF use & $35.4 \%$ & & $40.7 \%$ & & $37.3 \%$ & & $30.1 \%$ & & $36.1 \%$ & & $28.1 \%$ & & $8.0 \%$ \\
\hline $\begin{array}{l}\text { Mean }( \pm S D) \\
\text { SNF days }\end{array}$ & 13.0 & $(46.9)$ & 14.2 & $(40.1)$ & 11.8 & (32.8) & 6.9 & $(20.7)$ & 11.8 & $(38.1)$ & 9.6 & $(30.3)$ & 2.2 \\
\hline $\begin{array}{l}\text { Outpatient clinic } \\
\text { use }\end{array}$ & $95.5 \%$ & & $93.4 \%$ & & $95.1 \%$ & & $76.4 \%$ & & $91.1 \%$ & & $90.1 \%$ & & $1.0 \%$ \\
\hline Office visit use & $99.6 \%$ & & $99.6 \%$ & & $99.8 \%$ & & $98.8 \%$ & & $99.5 \%$ & & $96.3 \%$ & & $3.1 \%$ \\
\hline $\begin{array}{l}\text { Home health care } \\
\text { use }\end{array}$ & $54.5 \%$ & & $62.6 \%$ & & $63.9 \%$ & & $46.7 \%$ & & $57.0 \%$ & & $35.3 \%$ & & $21.8 \%$ \\
\hline
\end{tabular}

Source: Authors' calculations based on SEER-Medicare data, 1992-2005. Resource use calculated based on entire follow-up period, expressed on an annual basis.

'Difference between overall CRC cohort and comparison cohort. All P $<.001$.

SNF: Skilled nursing facilities

Note: Cohorts were matched on age, sex, and geographic region

seemed to disappear starting around 2002 among both CC and RC patients (Figure 2).

\section{Discussion}

Despite their shorter lifespans, about one-third more CC and RC patients were hospitalized than were matched controls, and CRC patients accrued about 10 more hospital days than did controls. CC patients were hospitalized more often than were RC patients in both inpatient and SNF settings, possibly because of the greater use of surgery in CC patients. RC patients used more home health and hospice services than did CC patients and, in the initial and terminal phases, were more likely to use office, outpatient, and inpatient services. Resource use was most intense among stage IV patients when analyzed per month of follow-up.

During our study period (1992-2005), we observed a marked increase in the percentage of beneficiaries who used hospice care. RC patients had slightly higher hospice use rates than did CC patients, which is interesting in light of the fact that RC patients have lower lifetime and perlifetime-year costs than do CC patients[17]. The observed increase in hospice use is in line with national trends in 

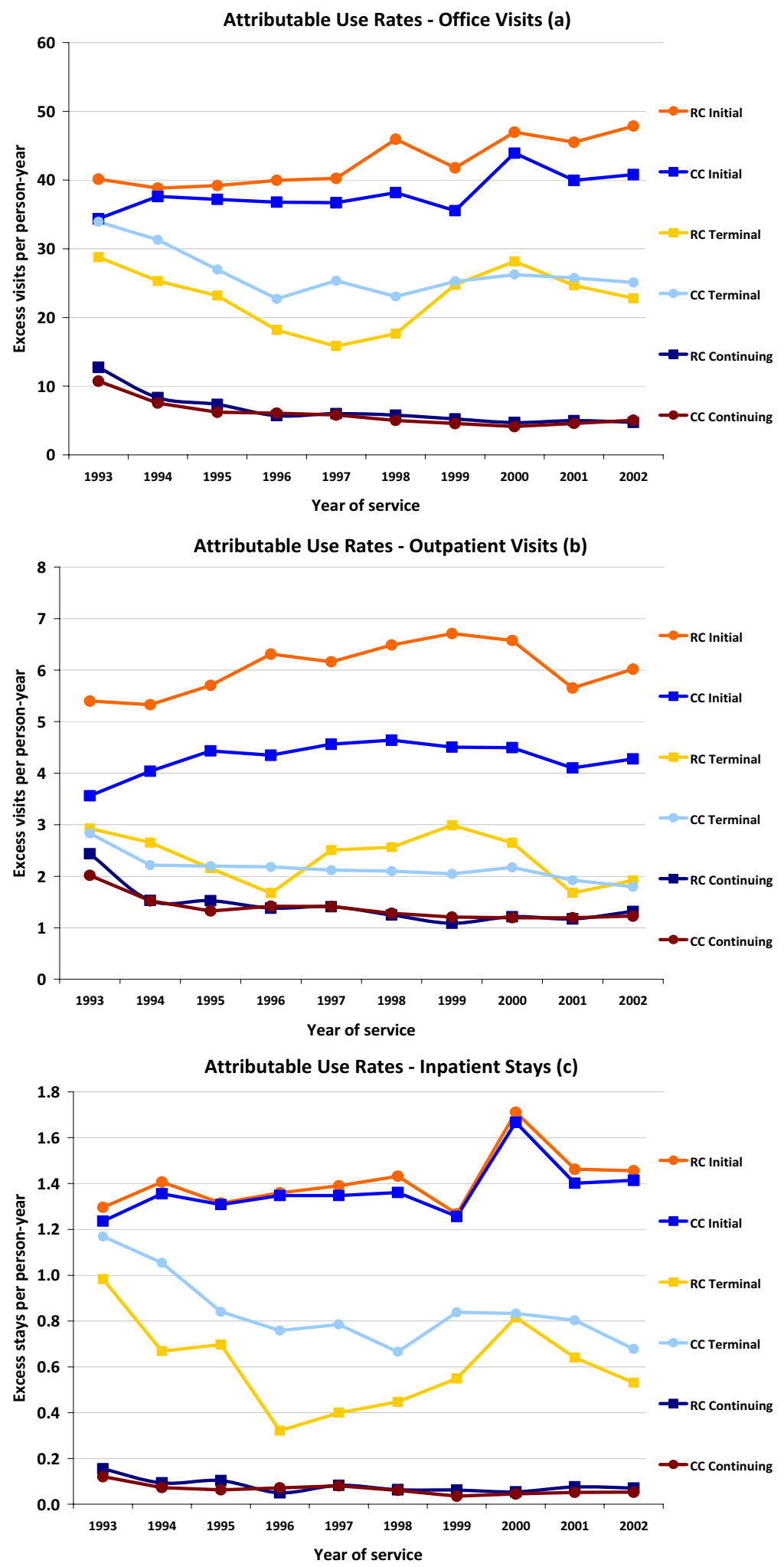

Figure I

Excess visits per person-year among patients with CRC, by treatment phase and year of service. 


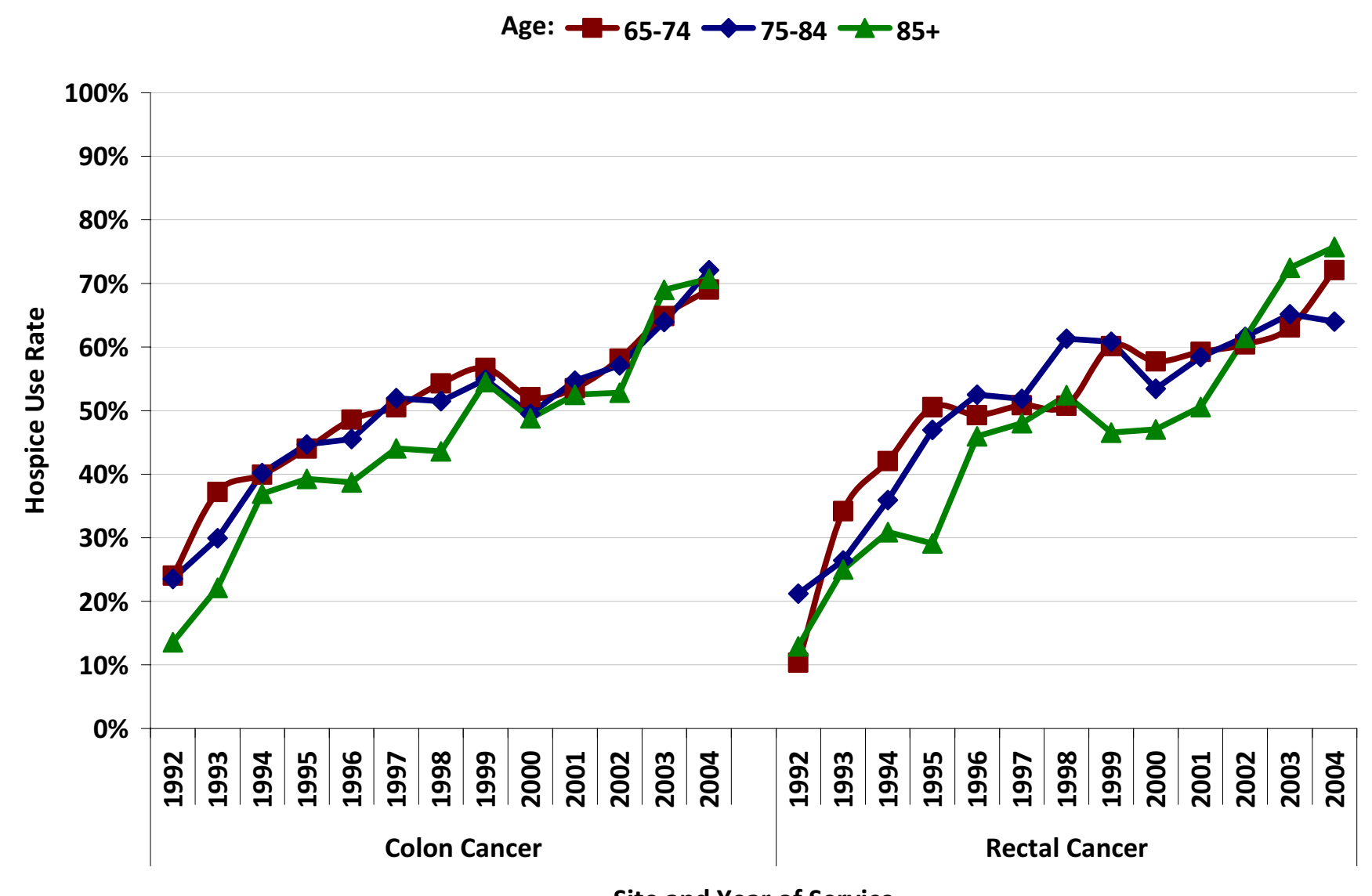

Figure 2

Hospice use rates among CRC patients who died of CRC, by age at death, year, and subsite.

hospice use that may have been fueled, in part, by an increase in the number of hospice providers[18]. Medicare spending on hospice services increased by $130 \%$ from 2000 to 2004, and the percent of all Medicare beneficiaries who use hospice care increased from 22\% in 2000 to $31 \%$ in 2004[18]. Given the potential clinical[19] and economic[20] benefits of hospice, it is noteworthy that hospice use increased so dramatically in our sample.

Few previous studies of CRC have included utilization data, and most have focused on hospice use. For example, Lackan et al found an overall hospice use rate of $30.2 \%$ among patients with breast, colorectal, lung, and prostate cancer who died between 1991 and 1999[3]. A study by Shugarman et al using 1993-1999 Medicare data to analyze age and gender differences in utilization rates for CRC patients in their last year of life found an overall hospice use rate of $48.0 \%$, with younger patients more likely to use hospice services[11]. As we have shown, it appears that hospice use differences by age may have smoothed somewhat in more recent years.
This study is subject to the limitations of the data source, including potential coding errors, incomplete data, and lack of generalizability to the non-Medicare population [21-23]. While the elderly comprise the majority of patients with CRC, this sample is not representative of all US CRC patients. Despite these limitations, SEER-Medicare data have been used in numerous published studies of CRC[24].

\section{Conclusion}

This retrospective database study of 13 years of data from over 70,000 CRC patients found that Medicare beneficiaries with CRC use significantly more resources than similar individuals without CRC. The most intense outpatient, inpatient, and office visit resource use was seen in the initial treatment phase. Over the study period, the use of hospice among those who died of CRC increased substantially, and age-related differences appear to have moderated over time. Our findings may be useful for understanding changes in costs and cost drivers over time, 
tracking trends, and forecasting resource needs for CRC patients in the future.

\section{Competing interests}

KL, LML, JRK, JM: Received research funding from GE Healthcare; DWL: Employee of GE Healthcare; CCE: Consultant for Boston Health Economics

\section{Authors' contributions}

$\mathrm{KL}, \mathrm{JM}, \mathrm{DWL}$, and $\mathrm{LML}$ designed the research methods. $\mathrm{KL}$, LML, and JRK collected and analyzed the data. All authors contributed to data interpretation, made substantive contributions to the manuscript, and had final approval of the article.

\section{Acknowledgements}

The authors gratefully acknowledge Rick deFriesse, MEd, for assistance with SAS programming and David Vanness, PhD and Gerald Riley, MSPH, for helpful comments on earlier versions of this work.

This study was sponsored by a grant from GE Healthcare, Waukesha, WI. An employee of the sponsor (DWL) was involved in the study design, analysis, and interpretation of data.

Portions of this study were presented in preliminary form at the $13^{\text {th }}$ Annual Meeting of the International Society for Pharmacoeconomics and Outcomes Research, Toronto, ON, May 5, 2008.

*At the time of the study, Dr. Earle was employed by Harvard Medical School (Cambridge, MA).

\section{References}

I. Cancer Facts \& Figures [http://www.cancer.org/docroot/STT/ STT 0.asp]

2. Yabroff KR, Mariotto AB, Feuer E, Brown ML: Projections of the costs associated with colorectal cancer care in the United States, 2000-2020. Health Econ 2007, I7(8):947-959.

3. Lackan NA, Ostir GV, Freeman JL, Mahnken JD, Goodwin JS: Decreasing variation in the use of hospice among older adults with breast, colorectal, lung, and prostate cancer. Med Care 2004, 42(2): I 16-122.

4. Lackan NA, Ostir GV, Freeman JL, Kuo YF, Zhang DD, Goodwin JS: Hospice use by Hispanic and non-Hispanic white cancer decedents. Health Serv Res 2004, 39(4 Pt I):969-983.

5. Lackan NA, Ostir GV, Kuo YF, Freeman JL: The association of marital status and hospice use in the USA. Palliat Med 2005, 19(2):160-162.

6. Cintron A, Hamel MB, Davis RB, Burns RB, Phillips RS, McCarthy EP: Hospitalization of hospice patients with cancer. J Palliat Med 2003, 6(5):757-768.

7. Ngo-Metzger Q, McCarthy EP, Burns RB, Davis RB, Li FP, Phillips RS: Older Asian Americans and Pacific Islanders dying of cancer use hospice less frequently than older white patients. $\mathrm{Am} J$ Med 2003, II 5(I):47-53.

8. McCarthy EP, Burns RB, Ngo-Metzger Q, Davis RB, Phillips RS: Hospice use among Medicare managed care and fee-for-service patients dying with cancer. JAMA 2003, 289(17):2238-2245.

9. McCarthy EP, Burns RB, Davis RB, Phillips RS: Barriers to hospice care among older patients dying with lung and colorectal cancer. J Clin Oncol 2003, 21 (4):728-735.

10. Earle CC, Neville BA, Landrum MB, Ayanian JZ, Block SD, Weeks JC: Trends in the aggressiveness of cancer care near the end of life. J Clin Oncol 2004, 22(2):3 I5-32I.

II. Shugarman LR, Bird CE, Schuster CR, Lynn J: Age and gender differences in Medicare expenditures at the end of life for colorectal cancer decedents. J Womens Health (Larchmt) 2007, 16(2):214-227.
12. Mols F, Helfenrath KA, Vingerhoets AJ, Coebergh JW, Poll-Franse LV van de: Increased health care utilization among long-term cancer survivors compared to the average Dutch population: a population-based study. Int J Cancer 2007, I 2 I (4):87|-877.

13. Warren JL, Klabunde CN, Schrag D, Bach PB, Riley GF: Overview of the SEER-Medicare data: content, research applications, and generalizability to the United States elderly population. Med Care 2002, 40(8 Suppl):3-I8.

14. Potosky AL, Riley GF, Lubitz JD, Mentnech RM, Kessler LG: Potential for cancer related health services research using a linked medicare-tumor registry database. Med Care 1993, $3 I(8): 732-748$.

15. About SEER [http://seer.cancer.gov/about/]

16. Deyo RA, Cherkin DC, Ciol MA: Adapting a clinical comorbidity index for use with ICD-9-CM administrative databases. J Clinical Epidemiology 1992, 45(6):613-619.

17. Lang K, Lines LM, Lee DW, Korn JR, Earle CC, Menzin J: Lifetime and treatment-phase costs associated with colorectal cancer: evidence from SEER-Medicare data. Clin Gastroenterol Hepatol 2009, 7(2): 198-204.

18. A data book: Healthcare spending and the Medicare program [http://www.medpac.gov/publications/congressional reports/ Jun06DataBook Entire report.pdf]

19. Connor SR, Pyenson B, Fitch K, Spence C, Iwasaki K: Comparing hospice and nonhospice patient survival among patients who die within a three-year window. J Pain Symptom Manage 2007, 33(3):238-246.

20. Taylor DH, Ostermann J, Van Houtven CH, Tulsky JA, Steinhauser K: What length of hospice use maximizes reduction in medical expenditures near death in the US Medicare program? Soc Sci Med 2007, 65(7): I466-1478.

21. Brown ML, Riley GF, Schussler N, Etzioni R: Estimating health care costs related to cancer treatment from SEER-Medicare data. Med Care 2002, 40(8 Suppl): I04- I7.

22. Izquierdo JN, Schoenbach VJ: The potential and limitations of data from population-based state cancer registries. Am J Public Health 2000, 90(5):695-8.

23. Schneeweiss $S$, Avorn J: A review of uses of health care utilization databases for epidemiologic research on therapeutics. J Clin Epidemiol 2005, 58(4):323-337.

24. Surveillance, Epidemiology, and End Results (SEER): Bibliography [http://seer.cancer.gov/cgi-bin-pubsearch/pubsearch/ index.pl\#results]

\section{Pre-publication history}

The pre-publication history for this paper can be accessed here:

\section{http://www.biomedcentral.com/1472-6963/9/227/pre}

pub

Publish with Biomed Central and every scientist can read your work free of charge

"BioMed Central will be the most significant development for disseminating the results of biomedical research in our lifetime. "

Sir Paul Nurse, Cancer Research UK

Your research papers will be:

- available free of charge to the entire biomedical community

- peer reviewed and published immediately upon acceptance

- cited in PubMed and archived on PubMed Central

- yours - you keep the copyright

Submit your manuscript here:

http://www.biomedcentral.com/info/publishing_adv.asp
BioMedcentral 